\title{
Use of Weight-Management Mobile Phone Apps in Saudi Arabia: A Web-Based Survey
}

Ghadeer S Aljuraiban, $\mathrm{PhD}$

Department of Community Health Sciences, College of Applied Medical Sciences, King Saud University, Riyadh, Saudi Arabia

\section{Corresponding Author:}

Ghadeer S Aljuraiban, PhD

Department of Community Health Sciences

College of Applied Medical Sciences

King Saud University

Turki Alawwal

Riyadh, 145111

Saudi Arabia

Phone: 96614651122

Email: galjuraiban@ksu.edu.sa

\section{Abstract}

Background: In recent years, the use of mobile phone weight-management apps has increased significantly. Weight-management apps have been found effective in promoting health and managing weight. However, data on user perception and on barriers to app usage are scarce.

Objective: This study aimed to investigate the use of weight-management apps and barriers to use as well as reasons for discontinuing use in a sample of mobile phone users in Saudi Arabia.

Methods: Mobile phone users aged 18 years and above from the general public in Saudi Arabia completed a Web-based survey. The survey included questions on weight-management app usage patterns, user perceptions concerning weight management, efficacy of weight-management apps, and reasons for discontinuing use. Participants were classified into normal weight (body mass index [BMI]: 18.5 to $24.9 \mathrm{~kg} / \mathrm{m}^{2}$ ) and overweight or obese (BMI: $\geq 25.0 \mathrm{~kg} / \mathrm{m}^{2}$ ).

Results: The survey included 1191 participants; 513 of them used weight-management apps. More overweight or obese respondents used these apps compared with normal weight respondents (319/513, 62.2\% vs 194/513, 37.8\%, respectively). App features that overweight or obese users were most interested in were mainly the possibility to be monitored by a specialist and barcode identification of calorie content, whereas normal weight users mostly preferred availability of nutrition information of food items. Reasons for discontinuing use among overweight or obese respondents were mainly that monitoring by a specialist was not offered $(80 / 236,33.9 \%)$ and the app was not in the local language $(48 / 236,20.3 \%)$. Among normal weight users, the main reason for noncontinuance was the app language $(45 / 144,31.3 \%)$ and difficulty of use $(30 / 144,20.8 \%)$.

Conclusions: To better address the needs of both normal weight and overweight or obese adults, improved app designs that offer monitoring by a specialist are needed. Developers may consider ways of overcoming barriers to use, such as language, by developing local language apps, which can improve the efficacy of such apps and help spread their use.

(JMIR Mhealth Uhealth 2019;7(2):e12692) doi: $\underline{10.2196 / 12692}$

\section{KEYWORDS}

lifestyle; mobile app; weight loss; mobile phone

\section{Introduction}

\section{Background}

Long-term analyses of trends in body mass index (BMI) levels show that obesity increased globally between 1980 and 2008 [1]. In 2013, a national survey reported that the prevalence of obesity in Saudi adults was $29 \%$ and was higher in women compared with men (33.5\% vs $24.1 \%$, respectively) [2]; by 2022 , prevalence is expected to increase to $40 \%$ for men and $78 \%$ for women [3]. Several interventions including lifestyle and dietary modifications have been shown to be effective in the management of obesity; however, limitations such as financial cost and accessibility may restrict their use [4,5]. 
A recent, encouraging development is the marked increase in the number of mobile phone apps for weight loss or weight management [6-9]. According to the 2018 Global Mobile Market Report, Saudi Arabia has one of the highest mobile phone penetration rates in the world [10]. In 2017, Saudi Arabia had 21 million mobile phone users (84\% of total adults); this is expected to increase to nearly 24 million in 2022 [11]. Mobile phone apps that focus on health have achieved worldwide popularity; over 325,000 health, fitness, and medical apps were available for download on all major app stores in 2017 [12].

With the projected epidemic in increasing obesity, frequent recording of both food intake and physical activity with weight-management apps may be a useful, potentially cost-effective and conveniently available method for modifying health-related behaviors [13]. A systematic review and meta-analysis of 12 randomized controlled trials and case-control studies showed that use of weight-management apps affected BMI by a net reduction of $0.4 \mathrm{~kg} / \mathrm{m}^{2}$ more than control groups (ie, traditional interventions or intensive counseling) [14].

\section{Rational and Aim}

Development and use of weight-management apps is still in an early phase, and sample populations in various countries have reported barriers such as limited functionality, lack of input options for tracking data, no evidence-based guidelines, and improper app classification (ie, only one-fifth of the apps classified as health and fitness or medical actually facilitated behavioral or physical activity; many simply offered health information) [15]. There is a paucity of evidence regarding usage and barriers of use in Saudi Arabia. One qualitative study restricted to Saudi women only reported that the available weight-management apps offered diet programs that lacked locally available foods and suggested physical activities that were not applicable to their environment [16].

Despite growing research on weight-management apps, evidence on user perspective-especially among users in Saudi Arabia, whose perspective varies vastly from that of the West-has been little explored. To the author's knowledge, this is the first survey aimed to identify the sociodemographic characteristics of weight-management app users, app usage patterns, user perceptions, efficacy, and reasons for continuing or discontinuing use of a weight-management phone app in Saudi Arabia.

\section{Methods}

\section{Design and Sample}

From May to July 2018, mobile phone users aged 18 years and older from the general public in the city of Riyadh filled out an open Web-based survey. The survey was designed using Microsoft Forms (Microsoft Corp). Authentication cookies prevented multiple entries from the same individual. The survey adhered to advanced Web-based survey methodology, such as internet protocol address verification. The multifaceted recruitment strategy included university portals, social media, newsletters, and posters, all citing a quick response code for declaring interest. Those outside of the internet-based survey were not contacted. Of the 1302 visitors to the survey link, 1191 agreed to participate; all of the participants resided in Riyadh. Of these 1191, a total of 513 reported having previously downloaded an app to track their weight and completed all survey items. No personal identifying information was collected. The King Saud University Institutional Review Board approved all study procedures (reference \# KSU-HE-18-1006).

\section{Survey Items}

The survey comprised 28 items in the following domains: (1) sociodemographic characteristics (gender, age, employment, education, and income), (2) general health questions (weight, height, physical activity, smoking habits, and medical history), (3) usage patterns (number of apps used, frequency of use, reasons for use, and desired features), (4) user conceptions and efficacy of weight-management apps (effectiveness of weight-reduction apps, effectiveness of fitness apps, and effectiveness of long-term use), and (5) reasons for discontinuing use (number of apps that the respondent no longer uses and reasons for discontinuing use).

Krebs et al previously used the survey questions in their national survey throughout the United States [17]. As the survey items on app use had no known precedent, a team of experts with expertise in questionnaire design field-tested the items among researchers. The Web-based survey administration system was also pretested and then pilot-tested live for 1 day, attracting 86 respondents. These data, however, were not included in the final analysis of this study but were analyzed to adjust the Web-based survey for errors.

The items were presented in a logical order, and consideration was taken to reduce response set bias. Each question required a response before the respondent was allowed to advance to the next screen. The Web-based survey displayed 1 item per screen, with the first screen asking respondents for their informed consent to participate in the study. Following consent, participants were allowed to begin the survey. Participation was completely voluntary. A back button on each screen allowed participants to edit previous answers. The average time needed to complete the survey was about $8 \mathrm{~min}$.

\section{Statistical Analysis}

Statistical analyses were conducted using JMP (version 12; SAS Institute). No statistical correction procedures or weightings were applied. Categorical variables are presented as percentages, whereas continuous variables are presented as means and SDs. Participants were stratified by gender and by BMI, where participants were considered of normal weight if their BMI was 18.5 to $24.9 \mathrm{~kg} / \mathrm{m}^{2}$ and overweight or obese if their BMI was $\geq 25 \mathrm{~kg} / \mathrm{m}^{2}$.

Sample size was calculated based on the current population of Riyadh - the capital of Saudi Arabia has 5.5 million adults aged above 18 years [18] and $84 \%$ are mobile phone users [11] — using a confidence level of $95 \%$ and a precision of $5 \%$. With these parameters, the minimum sample required for the analyses to have a power of $95 \%$ would be 207 individuals. 


\section{Results}

\section{Sociodemographic Characteristics and Health Status}

Of the respondents, $43.07 \%$ (513/1191) reported that they had previously used an app to manage their weight; only analyses for weight-management app users are presented (Table 1). More overweight or obese respondents reported that they had previously used an app to track their weight compared with normal-weight respondents (319/513, 62.2\% vs 194/513, 37.8\%, respectively; Table 2). Most users were Saudi nationals $(487 / 513,94.9 \%)$, women $(305 / 513,59.5 \%)$, had a mean age of 26.6 (SD 8.1) years, and a mean BMI of 28.6 (SD 6.7) kg/m². Most users were also educated and had a high monthly income. The majority of the female respondents were overweight or obese (178/305, 59.5\%). Most users (399/513, 77.8\%) considered their general health to be good, very good, or excellent. The analyses found gender differences in lifestyle: men were more likely to smoke than women, and more women reported that they never engaged in physical activity (Multimedia Appendix 1).

\section{Usage Patterns}

Most weight-management app users used 1 to 5 apps (476/513, $92.8 \%$; Table 2). The frequency of use was less than once a month for $34.9 \%(179 / 513)$ or a few times a week for $22.0 \%$ (113/513). In overweight or obese users, the most common reasons for wanting to download a weight-management app were to lose weight $(134 / 319,42.0 \%)$ and monitor food intake (88/319, 27.6\%; Table 2). Normal-weight participants, on the other hand, downloaded a weight-management app mainly to monitor food intake $(82 / 194,42.3 \%)$ and track physical activity (52/194, 26.8\%). The most common reasons for downloading a particular weight-management app were its rank in the app store, recommendations from friends and family (154/513, $30.0 \%)$, and social media influencers $(93 / 513,18.1 \%$; Table 2$)$.

The app features that overweight or obese users were most interested in were (1) the possibility to be monitored by a specialist $(126 / 319,39.5 \%)$, (2) barcode identification of calorie content $(77 / 319,24.1 \%)$, (3) availability of nutrition information on numerous food items $(56 / 319,17.6 \%)$, (4) a weekly or monthly progress report $(44 / 319,13.8 \%)$, and (5) constant reminders to follow a chosen diet or exercise $(16 / 319,5.0 \%)$. For normal-weight users, the desired features were (1) availability of nutrition information on numerous food items (67/194, 34.5\%), (2) barcode identification of calorie content $(54 / 194,27.8 \%)$, (3) the possibility to be monitored by a specialist $(31 / 194,16.0 \%)$, (4) a weekly or monthly progress report $(26 / 194,13.4 \%)$, and (5) constant reminders to follow a chosen diet or exercise $(16 / 194,8.3 \%$; Table 2$)$. No gender differences in usage patterns were observed (Multimedia Appendix 2).

\section{User Conceptions and Efficacy of Weight-Management Apps}

Most weight-management app users agreed or strongly agreed that apps were helpful in losing weight (Table 3). More normal-weight users agreed or strongly agreed that weight-management apps had helped them lose weight compared with overweight or obese users $(98 / 194,50.5 \%$ vs $148 / 319$, 46.4\%; Table 3). As for apps that suggested exercise plans, more normal-weight users agreed or strongly agreed that such apps helped them lose weight compared with overweight or obese respondents (116/194, 59.8\% vs 177/319, 55.5\%, respectively; Table 3).

Concerning efficacy, overweight or obese users were unsure whether weight-management apps would be effective in the long term $(170 / 319,53.3 \%)$, whereas normal-weight users agreed or strongly agreed that they were effective (102/194, $52.6 \%$; Table 3). No gender differences were observed (Multimedia Appendix 3).

\section{Reasons for Discontinuing Use}

Most users $(380 / 513,74.1 \%)$ reported that they have downloaded weight-management apps they no longer use, and the majority of these were overweight or obese $(236 / 380,62.1 \%$; Table 4). Among overweight or obese users, reasons for discontinuing use included (1) monitoring by a specialist was not offered $(80 / 236,33.9 \%)$, (2) the app language was not the local language $(48 / 236,20.3 \%)$, (3) some costs of app usage were hidden $(37 / 236,15.7 \%)$, (4) the app was confusing to use $(34 / 236,14.4 \%)$, and (5) the respondent had lost interest (30/236, 12.7\%). Normal-weight users stopped using an app because (1) it was not in the local language $(45 / 144,31.3 \%)$, (2) it was confusing to use $(30 / 144,20.8 \%)$, (3) it did not offer monitoring by a specialist, and (4) some costs were hidden $(21 / 144,14.6 \%)$. Reasons for discontinuing use were similar between men and women (Multimedia Appendix 4). 
Table 1. Sociodemographic characteristics and health status of participants stratified by body mass index.

\begin{tabular}{|c|c|c|c|}
\hline \multirow[t]{2}{*}{ Characteristics } & \multicolumn{2}{|l|}{ Body mass index } & \multirow[t]{2}{*}{ Total } \\
\hline & 18.5 to $24.9 \mathrm{~kg} / \mathrm{m}^{2}$ & $>25 \mathrm{~kg} / \mathrm{m}^{2}$ & \\
\hline \multicolumn{4}{|c|}{ Previously downloaded an app to track anything related to weight, $n(\%)$} \\
\hline No & $283(59.33)$ & $395(55.32)$ & $678(56.93)$ \\
\hline Yes & $194(40.67)$ & $319(44.68)$ & $513(43.07)$ \\
\hline \multicolumn{4}{|l|}{ Gender, $\mathbf{n}(\%)$} \\
\hline Female & $127(65.46)$ & $178(55.80)$ & $305(59.45)$ \\
\hline Male & $67(34.54)$ & $141(44.20)$ & $208(40.55)$ \\
\hline \multicolumn{4}{|l|}{ Nationality, n (\%) } \\
\hline Non-Saudi & $8(4.12)$ & $18(5.64)$ & $26(5.07)$ \\
\hline Saudi & $186(95.88)$ & $301(94.36)$ & $487(94.93)$ \\
\hline Age (years), mean (SD) & $24.4(6.9)$ & $27.7(8.3)$ & - \\
\hline \multicolumn{4}{|l|}{ Employment, n (\%) } \\
\hline In school & $122(62.89)$ & $161(50.47)$ & $283(55.17)$ \\
\hline Not working or retired & $7(3.61)$ & $20(6.27)$ & $27(5.26)$ \\
\hline Working full-time & $65(33.51)$ & $138(43.26)$ & $203(39.57)$ \\
\hline \multicolumn{4}{|l|}{ Education, n (\%) } \\
\hline High school degree & $42(21.65)$ & $45(14.11)$ & $87(16.96)$ \\
\hline Bachelor's degree & $122(62.89)$ & $189(59.25)$ & $311(60.62)$ \\
\hline Graduate degree (Masters, $\mathrm{PhD}$, or MD) & $30(15.46)$ & $85(26.65)$ & $115(22.42)$ \\
\hline \multicolumn{4}{|l|}{ Household income, $\mathbf{n}(\%)$} \\
\hline Less than $5,000 \mathrm{SR} /$ month & $7(3.61)$ & $20(6.27)$ & $27(5.26)$ \\
\hline 5,100 to $10,000 \mathrm{SR} / \mathrm{month}$ & $55(28.35)$ & $93(29.15)$ & $148(28.85)$ \\
\hline 10,100 to $20,000 \mathrm{SR} /$ month & $76(39.18)$ & $105(32.92)$ & $181(35.28)$ \\
\hline$>20,000 \mathrm{SR} / \mathrm{month}$ & $56(28.87)$ & $101(31.66)$ & $157(30.60)$ \\
\hline \multicolumn{4}{|l|}{ General health status, $\mathbf{n}(\%)$} \\
\hline Poor & $2(1.03)$ & $14(4.39)$ & $16(3.12)$ \\
\hline Average & $32(16.49)$ & $66(20.69)$ & $98(19.10)$ \\
\hline Good & $22(11.34)$ & $43(13.48)$ & $65(12.67)$ \\
\hline Very good & $80(41.24)$ & $112(35.11)$ & $192(37.43)$ \\
\hline Excellent & $58(29.90)$ & $84(26.33)$ & $142(27.68)$ \\
\hline \multicolumn{4}{|c|}{ Frequency of exercise or physical activity for at least $15 \mathrm{~min}$ in the past week, $\mathbf{n}(\%)$} \\
\hline Never & $55(28.35)$ & $119(37.30)$ & $174(33.92)$ \\
\hline 1 day & $28(14.43)$ & $23(7.21)$ & $51(9.94)$ \\
\hline 2 days & $39(20.10)$ & $49(15.36)$ & $88(17.15)$ \\
\hline 3-4 days & $39(20.10)$ & $66(20.69)$ & $105(20.47)$ \\
\hline 5-7 days & $33(17.01)$ & $62(19.44)$ & $95(18.52)$ \\
\hline \multicolumn{4}{|l|}{ Overall nutritional status of the diet, $n(\%)$} \\
\hline Poor & $22(11.34)$ & $80(25.08)$ & $102(19.88)$ \\
\hline Fair & $39(20.10)$ & $77(24.14)$ & $116(22.61)$ \\
\hline Good & $62(31.96)$ & $111(34.80)$ & $173(33.72)$ \\
\hline Very good & $59(30.41)$ & $45(14.11)$ & $104(20.27)$ \\
\hline Excellent & $12(6.19)$ & $6(1.88)$ & $18(3.51)$ \\
\hline
\end{tabular}




\begin{tabular}{|c|c|c|c|}
\hline \multirow[t]{2}{*}{ Characteristics } & \multicolumn{2}{|l|}{ Body mass index } & \multirow[t]{2}{*}{ Total } \\
\hline & 18.5 to $24.9 \mathrm{~kg} / \mathrm{m}^{2}$ & $>25 \mathrm{~kg} / \mathrm{m}^{2}$ & \\
\hline \multicolumn{4}{|l|}{ Smoking, n (\%) } \\
\hline Yes & $23(11.86)$ & $53(16.61)$ & $76(14.81)$ \\
\hline No & $171(88.14)$ & $266(83.39)$ & 437 (85.19) \\
\hline \multicolumn{4}{|l|}{ Co-morbidities, n (\%) } \\
\hline None & $135(69.59)$ & $212(66.46)$ & $347(67.64)$ \\
\hline Hypercholesterolemia & $9(4.64)$ & $8(2.51)$ & $17(3.31)$ \\
\hline Hypertension & $9(4.64)$ & $9(2.82)$ & $18(3.51)$ \\
\hline Depression & $8(4.12)$ & $46(14.42)$ & $54(10.53)$ \\
\hline Diabetes & $21(10.82)$ & $21(6.58)$ & $42(8.19)$ \\
\hline Other chronic disease & $12(6.19)$ & $23(7.21)$ & $35(6.82)$ \\
\hline
\end{tabular}


Table 2. Pattern of use of weight-management apps stratified by body mass index.

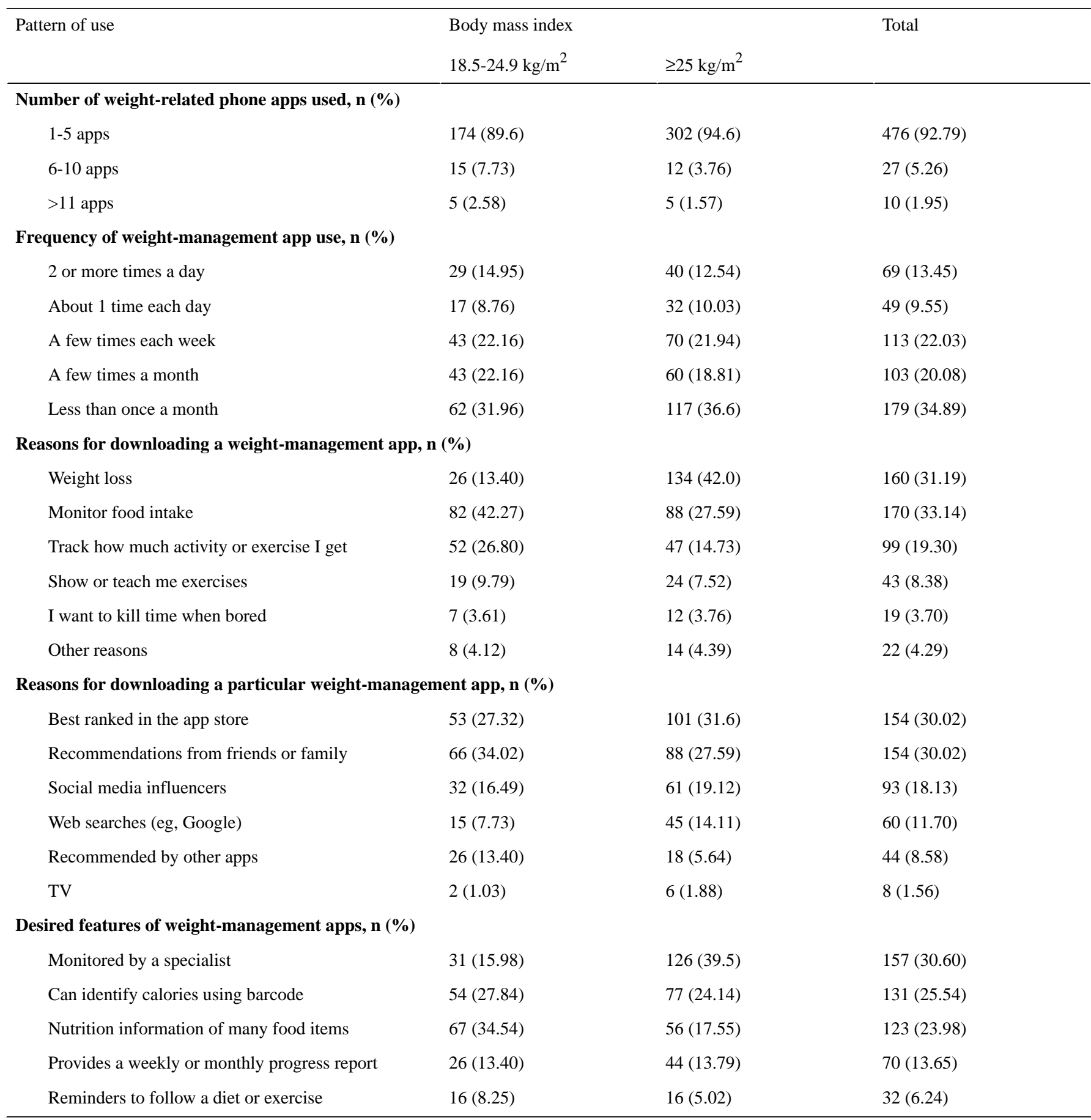


Table 3. User conceptions and efficacy of weight-management apps stratified by body mass index.

\begin{tabular}{|c|c|c|c|}
\hline \multirow[t]{2}{*}{ User conceptions } & \multicolumn{2}{|l|}{ Body mass index } & \multirow[t]{2}{*}{ Total } \\
\hline & $18.5-24.9 \mathrm{~kg} / \mathrm{m}^{2}$ & $>25 \mathrm{~kg} / \mathrm{m}^{2}$ & \\
\hline \multicolumn{4}{|c|}{ Apps that provide a weight-reduction meal plan helped in managing weight, $n(\%)$} \\
\hline Strongly disagree & $65(33.51)$ & $74(23.20)$ & $139(27.10)$ \\
\hline Disagree & $11(5.67)$ & $19(5.96)$ & $30(5.85)$ \\
\hline Unsure & $20(10.31)$ & $78(24.45)$ & $98(19.10)$ \\
\hline Agree & $82(42.27)$ & $125(39.18)$ & $207(40.35)$ \\
\hline Strongly agree & $16(8.25)$ & $23(7.21)$ & $39(7.60)$ \\
\hline \multicolumn{4}{|c|}{ Apps that provide an exercise plan helped in managing weight, $\mathbf{n}(\%)$} \\
\hline Strongly disagree & $51(26.29)$ & $71(22.26)$ & $122(23.78)$ \\
\hline Disagree & $9(4.64)$ & $15(4.70)$ & $24(4.68)$ \\
\hline Unsure & $18(9.28)$ & $56(17.55)$ & $74(14.42)$ \\
\hline Agree & $96(49.48)$ & $148(46.39)$ & $244(47.56)$ \\
\hline Strongly agree & $20(10.31)$ & $29(9.09)$ & $49(9.55)$ \\
\hline \multicolumn{4}{|c|}{ Weight-management apps are effective for long-term use, $n(\%)$} \\
\hline Strongly disagree & $50(25.77)$ & $52(16.30)$ & $102(19.88)$ \\
\hline Disagree & $0(0.00)$ & $7(2.19)$ & $7(1.36)$ \\
\hline Unsure & $42(21.65)$ & $170(53.29)$ & $212(41.33)$ \\
\hline Agree & $80(41.24)$ & $60(18.81)$ & $140(27.29)$ \\
\hline Strongly agree & $22(11.34)$ & $30(9.40)$ & $52(10.14)$ \\
\hline
\end{tabular}

Table 4. Reasons for discontinuing use, stratified by body mass index.

\begin{tabular}{|c|c|c|c|}
\hline \multirow[t]{2}{*}{ Reasons for discontinuing use } & \multicolumn{2}{|l|}{ Body mass index } & \multirow[t]{2}{*}{ Total } \\
\hline & $18.5-24.9 \mathrm{~kg} / \mathrm{m}^{2}$ & $>25 \mathrm{~kg} / \mathrm{m}^{2}$ & \\
\hline \multicolumn{4}{|c|}{ Have you downloaded any weight management apps that you no longer use? n (\%) } \\
\hline No & $50(25.77)$ & $83(26.02)$ & $133(25.93)$ \\
\hline Yes & $144(74.23)$ & $236(73.98)$ & $380(74.07)$ \\
\hline \multicolumn{4}{|l|}{ Why do you no longer use them? n (\%) } \\
\hline Monitoring by a specialist was not offered & $21(14.58)$ & $80(33.90)$ & $101(26.58)$ \\
\hline The app language was not in the local language & $45(31.25)$ & $48(20.34)$ & $93(24.47)$ \\
\hline There were hidden costs & $21(14.58)$ & $37(15.68)$ & $58(15.26)$ \\
\hline Loss of interest & $17(11.81)$ & $30(12.71)$ & $47(12.37)$ \\
\hline The app was confusing to use & $30(20.83)$ & $34(14.41)$ & $64(16.84)$ \\
\hline I no longer need it, or I met my goals & $10(6.94)$ & $7(2.97)$ & $17(4.47)$ \\
\hline
\end{tabular}

\section{Discussion}

\section{Principal Findings}

The survey found that only $43 \%$ of respondents used weight-management apps. Most users were young, educated women with a high income, and were overweight or obese. Overweight or obese users download a weight-management app mostly to lose weight, whereas normal-weight participants, on the contrary, download a weight-management app mainly to monitor food intake and track physical activity. The feature of the weight-management app that overweight or obese users desired most was the possibility to be monitored by a specialist, whereas the least desired feature was the constant reminders to follow a diet or exercise. On the contrary, normal-weight participants mainly desired apps that could provide nutrition information and calorie content of food items through barcode identification.

Among all users of a weight-management app, this study found that one of the main reasons for discontinuing use was that the language of the app was not the local language of the user. 
Among overweight or obese users, another main reason was lack of monitoring by a specialist, and among normal-weight users, difficulty of use.

\section{Comparison With Previous Work}

In this study, $43 \%$ of the study sample currently used weight-management apps. A similar survey by Krebs and Duncan showed health app use among US adults to be about $60 \%$ [17]. Cultural differences and the newness of app use for health and weight management in the Saudi population may explain the difference [19].

Findings regarding the characteristics of weight-management app users in our survey are consistent with the results of a previous large-scale study in the United States [20]; we also found that most participants were young, had a higher income, had higher education, and reported very good or excellent health. Age and education were found to be important predictors for using mobile phones and apps as younger people are more exposed to mobile technology than the elderly, resulting in a higher utilization of mobile health-related apps [21]. We also found that the highest use of weight-management apps was among women. Women's high use of weight-management apps in our study is in line with previous investigations that showed women were more concerned about their health status and tended to follow a healthier dietary pattern than men [22]. We also found more overweight or obese participants used such apps (mostly to lose weight) compared with normal-weight participants, who mostly wanted to maintain their weight. This is consistent with a previous study showing that weight-management apps were mostly downloaded by overweight or obese users, which may be because these users are more concerned about their overall health than others [23].

We found that overweight or obese participants mostly preferred to be monitored by a specialist compared with other features of the app such as constant reminders to follow a diet or exercise. A previous intervention found that, for encouraging healthy behavior, individually tailored feedback and action plans were preferable to general health instructions [24]. A randomized controlled trial showed that individualized health apps were more effective in addressing patients' needs and provided the high-quality information and support required by patients [25]. In our survey, the most frequent reason for downloading a weight-management app, as reported by overweight or obese users, was to reduce caloric intake, whereas normal-weight users wanted to monitor their food intake. Among US health-related app users, Krebs et al found that the main reason for downloading apps was to track how much physical activity they were getting (52.8\%) [17]. Their findings, however, did not differentiate between normal weight and overweight or obese users. The difference in preference may be related to cultural and social variables in Saudi Arabia rather than biological reasons, although activities such as walking for women is generally acceptable in major cities; this is not always the case in rural parts of the country [26].

As for efficacy of use, more normal-weight users found that weight-management apps helped them lose weight compared with overweight or obese users. A randomized controlled trial, however, found that apps for weight loss did not affect the weight of overweight primary care patients and were only useful for individuals who were willing to self-monitor their calories [27].

Participants in our survey also tended to discontinue use of the app for various reasons such as monitoring by a specialist was not offered and app was not in the local language. Similar barriers were reported in a previous qualitative study on the challenges of app use in supporting health behavior changes, showing that users generally found health apps to be time consuming, have unexpected costs, and lack the possibility of consulting an expert [28]. A previous qualitative study restricted to Saudi women only reported that only a few obese or overweight women were aware of the availability of weight-management apps and reported barriers of app use to be lack of motivational support and the language of the app [16].

\section{Strengths and Limitations}

The strength of this study is that it is the first of its kind to target app users in Saudi Arabia. Additionally, it provides information on the demographics of this particular region along with insight into the extent of weight-management app use and barriers of use, which varies from barriers in other regions. This study also highlighted that weight-management apps are not only used by overweight or obese adults but also by normal-weight adults who wish to maintain their weight. Data on the differences in perception of use between overweight and normal-weight adults are also provided.

Although this is the first study to characterize user perspective on weight-management apps in Riyadh, Saudi Arabia, there were a few limitations. The main limitation was study design; a causal relationship cannot be inferred, and usage patterns may change over time. Second, the study sample included the city of Riyadh only and was not representative of the general population. A third limitation was the self-recorded weight and height of participants, which is a possible source of error. Finally, as this was a convenience sample, it did not include individuals who are overweight or obese but do not own mobile phones, although a large percentage of the population use mobile phones.

\section{Conclusions}

Although the majority of users believe that weight-management apps are efficacious, considerable challenges remain. Given the increasing prevalence of overweight and obesity in Saudi Arabia and the high accessibility to mobile phones among adults, app developers should address findings of this study, especially regarding reasons for use and discontinuance. More specifically, app developers should consider the aforementioned barriers by developing apps in local languages and by developing apps which are linked to health professionals to provide individualized plans to manage the weight of both normal and overweight adults. 


\section{Acknowledgments}

This research project was supported by a grant from the Research Center of the Female Scientific and Medical Colleges, Deanship of Scientific Research, King Saud University.

\section{Conflicts of Interest}

None declared.

\section{Multimedia Appendix 1}

Sociodemographic characteristics and health status of participants stratified by gender.

[PDF File (Adobe PDF File), 114KB-Multimedia Appendix 1]

\section{Multimedia Appendix 2}

Pattern of use of weight-management apps stratified by gender.

[PDF File (Adobe PDF File), 96KB-Multimedia Appendix 2]

\section{Multimedia Appendix 3}

User conceptions and efficacy of weight-management apps stratified by gender.

[PDF File (Adobe PDF File), 89KB-Multimedia Appendix 3]

\section{Multimedia Appendix 4}

Reasons for discontinuing use stratified by gender.

[PDF File (Adobe PDF File), 85KB-Multimedia Appendix 4]

\section{References}

1. Finucane MM, Stevens GA, Cowan MJ, Danaei G, Lin JK, Paciorek CJ, Global Burden of Metabolic Risk Factors of Chronic Diseases Collaborating Group (Body Mass Index). National, regional, and global trends in body-mass index since 1980: systematic analysis of health examination surveys and epidemiological studies with 960 country-years and $9 \cdot 1$ million participants. Lancet 2011 Feb 12;377(9765):557-567 [FREE Full text] [doi: 10.1016/S0140-6736(10)62037-5] [Medline: 21295846]

2. Memish ZA, El Bcheraoui C, Tuffaha M, Robinson M, Daoud F, Jaber S, et al. Obesity and associated factors--Kingdom of Saudi Arabia, 2013. Prev Chronic Dis 2014 Oct 09;11:E174 [FREE Full text] [doi: 10.5888/pcd11.140236] [Medline: 25299980]

3. Al-Quwaidhi AJ, Pearce MS, Critchley JA, Sobngwi E, O'Flaherty M. Trends and future projections of the prevalence of adult obesity in Saudi Arabia, 1992-2022. East Mediterr Health J 2014 Oct;20(10):589-595. [Medline: 25356689]

4. Diabetes Prevention Program Research Group, Knowler WC, Fowler SE, Hamman RF, Christophi CA, Hoffman HJ, et al. 10-year follow-up of diabetes incidence and weight loss in the Diabetes Prevention Program Outcomes Study. Lancet 2009 Nov 14;374(9702):1677-1686 [FREE Full text] [doi: 10.1016/S0140-6736(09)61457-4] [Medline: 19878986]

5. Eddy DM, Schlessinger L, Kahn R. Clinical outcomes and cost-effectiveness of strategies for managing people at high risk for diabetes. Ann Intern Med 2005 Aug 16;143(4):251-264. [Medline: 16103469]

6. de Jongh T, Gurol-Urganci I, Vodopivec-Jamsek V, Car J, Atun R. Mobile phone messaging for facilitating self-management of long-term illnesses. Cochrane Database Syst Rev 2012 Dec 12;12:CD007459. [doi: 10.1002/14651858.CD007459.pub2] [Medline: 23235644]

7. Beratarrechea A, Lee AG, Willner JM, Jahangir E, Ciapponi A, Rubinstein A. The impact of mobile health interventions on chronic disease outcomes in developing countries: a systematic review. Telemed J E Health 2014 Jan;20(1):75-82 [FREE Full text] [doi: 10.1089/tmj.2012.0328] [Medline: 24205809]

8. Kim YJ, Rhee SY, Byun JK, Park SY, Hong SM, Chin SO, et al. A smartphone application significantly improved diabetes self-care activities with high user satisfaction. Diabetes Metab J 2015 Jun;39(3):207-217 [FREE Full text] [doi: 10.4093/dmj.2015.39.3.207] [Medline: 26124991]

9. Klasnja P, Pratt W. Healthcare in the pocket: mapping the space of mobile-phone health interventions. J Biomed Inform 2012 Feb;45(1):184-198 [FREE Full text] [doi: 10.1016/j.jbi.2011.08.017] [Medline: 21925288]

10. Newzoo. Top 50 Countries/Markets by Smartphone Users and Penetration URL: https://newzoo.com/insights/rankings/ top-50-countries-by-smartphone-penetration-and-users/ [accessed 2019-02-13] [WebCite Cache ID 769W1DJ9W] 
11. Statista. Number of smartphone users in Saudi Arabia from 2017 to 2023 (in millions)* URL: https://www.statista.com/ statistics/494616/smartphone-users-in-saudi-arabia/ [accessed 2019-02-13] [WebCite Cache ID 769XQKbV0]

12. Research2Guidance. 2017. mHealth Economics 2017 - Current Status and Future Trends in Mobile Health URL: https:/ /research2guidance.com/product/mhealth-economics-2017-current-status-and-future-trends-in-mobile-health/ [accessed 2019-02-13] [WebCite Cache ID 769XqTOFt]

13. Burke LE, Styn MA, Glanz K, Ewing LJ, Elci OU, Conroy MB, et al. SMART trial: a randomized clinical trial of self-monitoring in behavioral weight management-design and baseline findings. Contemp Clin Trials 2009 Nov;30(6):540-551 [FREE Full text] [doi: 10.1016/j.cct.2009.07.003] [Medline: 19665588]

14. Flores Mateo G, Granado-Font E, Ferré-Grau C, Montaña-Carreras X. Mobile phone apps to promote weight loss and increase physical activity: a systematic review and meta-analysis. J Med Internet Res 2015 Nov 10;17(11):e253 [FREE Full text] [doi: 10.2196/jmir.4836] [Medline: 26554314]

15. Murray A. Institute for Healthcare Informatics. 2013 Nov 1. Patient Apps for Improved Healthcare: From Novelty to Mainstream URL: http://moodle.univ-lille2.fr/pluginfile.php/215345/mod_resource/content/0/IIHI_Patient_Apps_Report. pdf [accessed 2019-02-17] [WebCite Cache ID 76G4msQuC]

16. Alnasser AA, Alkhalifa AS, Sathiaseelan A, Marais D. What overweight women want from a weight loss app: a qualitative study on arabic women. JMIR Mhealth Uhealth 2015 May 20;3(2):e41 [FREE Full text] [doi: 10.2196/mhealth.4409] [Medline: 25993907]

17. Krebs P, Duncan DT. Health app use among US mobile phone owners: a national survey. JMIR Mhealth Uhealth 2015 Nov 04;3(4):e101 [FREE Full text] [doi: 10.2196/mhealth.4924] [Medline: 26537656]

18. General Authority for Statistics. 2016. Demography Survey of the Kingdom of Saudi Arabia URL: https://www.stats.gov.sa/ $\underline{\text { en }}$

19. Alnasser AA, Amalraj RE, Sathiaseelan A, Al-Khalifa AS, Marais D. Do Arabic weight-loss apps adhere to evidence-informed practices? Transl Behav Med 2016 Dec;6(3):396-402 [FREE Full text] [doi: 10.1007/s13142-015-0347-7] [Medline: 27528528]

20. Carroll JK, Moorhead A, Bond R, LeBlanc WG, Petrella RJ, Fiscella K. Who uses mobile phone health apps and does use matter? A secondary data analytics approach. J Med Internet Res 2017 Dec 19;19(4):e125 [FREE Full text] [doi: 10.2196/jmir.5604] [Medline: 28428170]

21. Latif S, Rana R, Qadir J, Ali A, Imran MA, Younis MS. Mobile health in the developing world: review of literature and lessons from a case study. IEEE Access 2017;5:11540-11556. [doi: 10.1109/ACCESS.2017.2710800]

22. Beer-Borst S, Hercberg S, Morabia A, Bernstein M, Galan P, Galasso R, et al. Dietary patterns in six european populations: results from EURALIM, a collaborative European data harmonization and information campaign. Eur J Clin Nutr 2000 Mar;54(3):253-262. [Medline: 10713749$]$

23. Binks M, van Mierlo T. Utilization patterns and user characteristics of an ad libitum internet weight loss program. J Med Internet Res 2010;12(1):e9 [FREE Full text] [doi: 10.2196/jmir.1347] [Medline: 20350926]

24. de Vries H, Kremers SP, Smeets T, Brug J, Eijmael K. The effectiveness of tailored feedback and action plans in an intervention addressing multiple health behaviors. Am J Health Promot 2008 Jul;22(6):417-425. [doi: 10.4278/ajhp.22.6.417] [Medline: 18677882$]$

25. Weymann N, Härter M, Dirmaier J. A tailored, interactive health communication application for patients with type 2 diabetes: study protocol of a randomised controlled trial. BMC Med Inform Decis Mak 2013 Feb 13;13(1). [doi: 10.1186/1472-6947-13-24]

26. Al-Zalabani AH, Al-Hamdan NA, Saeed AA. The prevalence of physical activity and its socioeconomic correlates in Kingdom of Saudi Arabia: a cross-sectional population-based national survey. J Taibah Univ Med Sci 2015 Jun;10(2):208-215. [doi: 10.1016/j.jtumed.2014.11.001]

27. Laing BY, Mangione CM, Tseng C, Leng M, Vaisberg E, Mahida M, et al. Effectiveness of a smartphone application for weight loss compared with usual care in overweight primary care patients: a randomized, controlled trial. Ann Intern Med 2014 Nov 18;161(10 Suppl):S5-12 [FREE Full text] [doi: 10.7326/M13-3005] [Medline: 25402403]

28. Dennison L, Morrison L, Conway G, Yardley L. Opportunities and challenges for smartphone applications in supporting health behavior change: qualitative study. J Med Internet Res 2013 Apr 18;15(4):e86 [FREE Full text] [doi: 10.2196/jmir.2583] [Medline: 23598614]

\section{Abbreviations \\ BMI: body mass index}


Edited by G Eysenbach; submitted 05.11.18; peer-reviewed by S Boucher, J Alvarez Pitti, C Carrion, K Tamura, PH Lin; comments to author 05.01.19; revised version received 08.01.19; accepted 25.01.19; published 22.02.19

Please cite as:

Aljuraiban $G S$

Use of Weight-Management Mobile Phone Apps in Saudi Arabia: A Web-Based Survey

JMIR Mhealth Uhealth 2019;7(2):e12692

URL: http://mhealth.jmir.org/2019/2/e12692/

doi: $\underline{10.2196 / 12692}$

PMID: $\underline{30794205}$

(C)Gadeer S Aljuraiban. Originally published in JMIR Mhealth and Uhealth (http://mhealth.jmir.org), 22.02.2019. This is an open-access article distributed under the terms of the Creative Commons Attribution License (https://creativecommons.org/licenses/by/4.0/), which permits unrestricted use, distribution, and reproduction in any medium, provided the original work, first published in JMIR mhealth and uhealth, is properly cited. The complete bibliographic information, a link to the original publication on http://mhealth.jmir.org/, as well as this copyright and license information must be included. 